\title{
Identifying Barriers to Therapeutic Adherence in Type 2-Diabetes: A Complex and Multidimensional Clinical Issue
}

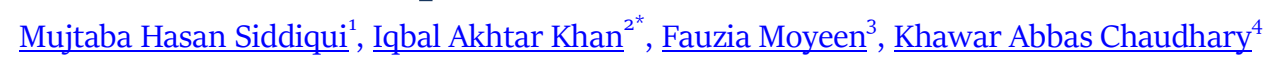

${ }^{1}$ Department of Medicine, Akhtar Saeed Medical \& Dental College, Lahore, Pakistan

${ }^{2}$ Independent Scholar, Lahore, Pakistan

${ }^{3}$ Consultant Diabetologoist, Diabetes Wellness Centre, Lahore, Pakistan

${ }^{4}$ Department of Medicine, Continental Medical College, Lahore, Pakistan

Corresponding Author: Prof. Iqbal Akhtar Khan, MBBS, DTM, FACTM, PhD

Address: Independent Scholar, Lahore, Pakistan.

Received date: 17 April 2019; Accepted date: 28 May 2019; Published date: 05 June 2019

Citation: Siddiqui MH, Khan IA, Moyeen F, et al., "Identifying Barriers to Therapeutic Adherence in Type 2Diabetes: A Complex and Multidimensional Clinical Issue”. Asp Biomed Clin Case Rep, vol.2, no.1: 22-28, 2019.

Copyright (C) 2019 Siddiqui MH, Khan IA, Moyeen F, et al., This is an open access article distributed under the Creative Commons Attribution License, which permits unrestricted use, distribution, and reproduction in any medium, provided the original work is properly cited.

\section{Abstract}

The problem of therapeutic non-adherence is a serious issue adversely affecting the adequate control and management of Typez Diabetes (T2D).This unwelcoming situation has been studied well on various spots on the globe, with diverse results. The present study, aimed at identifying the barriers to therapeutic adherence, was conducted on a set of proven cases of $\mathrm{T} 2 \mathrm{D}$, managed by primary healthcare providers. The adherence rate to medication alone was $42 \%$ while to medication plus lifestyle recommendations $27 \%$. Whereas sub-optimal health literacy, complexity of prescription and socioeconomic aspects were the main determinants, lapse on the part of healthcare system cannot be underscored. The present qualitative study was a preliminary investigation on a small sample. The magnitude of the problem necessitates that a large scale multi-centre in-depth quantitative study in 5 dimensions (recommended by WHO): socio-economic factors, health care team and system related factors, condition related factors, therapy related factors and patient related factors, be done on priority basis. This would pave the way for planning a well-designed intervention programme.

\section{Keywords}

Therapeutic Adherence; Typez Diabetes; Non-Adherence; Under-Adherence; Over-Adherence

\section{Quote}

"Surprisingly often, evidence based treatments fail to succeed because of the human factor known for a few decades as "patient's non-adherence". [1]

\section{Introduction}

Diabetes mellitus is a group of metabolic disorders characterized by hyperglycaemia resulting from defects in insulin secretion, action or both [2]. The type 2 diabetes (T2D), previously referred to as 'NIDDM' or 'Adult Onset' or 'Maturity Onset' or 'Maturity Onset of Young (MODY)' accounts for 90-95 $\%$ of those with diabetes. It is a complex interaction between genetic, behavioural and environmental factors [3].

Globally, an estimated 422 million adults were living with diabetes in 2014 compared to 108 million 
in 1980 rising from $4.7 \%$ to $8.5 \%$ in adult population .However, separate figures of prevalence for type 1 and type 2 do not exist. An estimated 1.6 million deaths are directly attributable to diabetes every year [4]. The prevalence of T2D, in Pakistan, as estimated in 2016, was $11.77 \%$ (M:F - 11.20\%:9.19\%) [5].

One of the major causes of uncontrolled T2D is patient's inadequate adherence to therapeutic regime. Adherence has been defined, by WHO, as "the extent to which a person's behaviour taking medication, following a diet, and/or executing lifestyle changes, corresponds with agreed recommendations from a health care provider"[3]. It is preferable to phrase it "Therapeutic Adherence", instead of 'Medication Adherence', as the former covers both pharmacological and non-pharmacological interventions.

Adherence, Compliance and Concordance are sometimes used interchangeably. However, adherence is an active choice of a patient to follow the instructions of the prescriber while taking the responsibility of his own wellbeing. Compliance, on the other side, is a passive behaviour in which the patient is following the list of instructions from the health care provider. Whereas, adherence and compliance relate to medicine taking behaviour of the patient, concordance refers to the interaction between the clinician and the patient. To quantify the issue of adherence, two more terms need to be clarified. Under -adherence has been defined as "having at least one medication with $<70 \%$ compliance and the Overadherence as having at least one medication with $>120 \%$ compliance" [6].

The patients' reasons for deviating from the agreed prescription are diverse and may be intentional or non-intentional [7].The intentional one refers to nonadherence that is deliberate and largely associated with patient's motivation whereas unintentional one is largely driven by a lack of capacity or resources [8]. The latter may be because of forgetfulness [9] or not knowing exactly how to use medicines [10]. It is important to note that the patients may become nonadherent during different stages of their treatment [11]. They may opt not to fill the prescription in pharmacy, overuse or underuse or even discontinue prematurely. The gravity of the disease is also an important factor for the patients because it motivates them to stick to the prescriber's instructions [12]. The nature of the ailment has its impact on the level of adherence. Van Geffen et al, from Netherlands, have demonstrated that from those prescribed antidepressants, $4.2 \%$ did not start the medication at all while $23.7 \%$ filled only a single prescription [13]. Conversely, adherence was found to be highest in those with HIV infection [13].

\section{Rationale}

Therapeutic non-adherence in diabetics is a serious clinical problem worldwide. A meta- analysis of 569 studies of medication adherence revealed an average non-adherence rate of $25 \%$ [14]. Whereas, WHO's definition of adherence focuses on patient's behaviour only, it does not indicate who is to be held responsible for this. The other notion, prevalent in our set up, is that incompetency of the prescriber is the main determinant.

The problem has been studied well on various spots on the globe, with diverse results. This is a preliminary investigation aimed at identifying the magnitude of the problem in local population.

\section{Patients and Methods}

\section{Objective:}

To identify the barriers to therapeutic adherence in individuals with Type 2 Diabetes

\section{Study Population:}

The present study was conducted on proven cases of uncomplicated $\mathrm{T} 2 \mathrm{D}$, on oral anti-hyperglycaemic pills, diagnosed and managed by primary care providers. The common reason for referral (by the care provider or by self) to the Diabetes Clinic was sub-optimal control of the disease. From amongst 108 such individuals, during the study period of March 2018 to February 2019, thirty three (M:F-18:15$55 \%: 45 \%$ ) were picked up. Their age ranged from 38 to 65 years, were of middle socioeconomic status and secondary level of education. They were evaluated by relevant laboratory work-up and clinical assessment; and their prescriptions reviewed accordingly. 


\section{Inclusion Criteria:}

- Those voluntarily willing to participate in the study

- Those on ambulatory care

\section{Exclusion Criteria:}

- Those with co-morbidities

- Those with cognitive dysfunction

- Females ,pregnant or lactating

Type of Study:

- Questionnaire based, descriptive, analytical

\section{Study Instruments:}

- Interviews, reviews of laboratory reports, clinical evaluation and free discussions with the participants, on monthly basis, to identify their diabetes related issues and level of satisfaction with the prescription medication and the recommendations for lifestyle modifications.

- The 'claims', at follow up visits by the participants' of 'all OK' or 'not OK' were scrutinized in the light of clinical evaluation and review of the lab work up.

\section{Results}

Contrary to the old notion that all faults lie with non-cooperative patient or the incompetent prescriber, the barriers to optimal therapeutic adherence were identified at following dimensions:

\section{The Patient:}

- Inadequate knowledge of the nature of his/her own illness.

- Insufficient information of consequences of nonadherence/ under-adherence of the prescription medication.

- Recourse to diverse care-providers (homeopaths, herbal medicine, natural healers, faith healers etc.) for additional/alternate advice, with resultant reduced trust in the efficacy of prescription medication.

- Manipulating the prescription medication by altering, substituting, pausing or even stopping part thereof.

- Undermining (or even ignoring) the advice of life style modification.

- Intentional non-adherence.

\section{The Prescriber:}

- Lapse on his/her part to provide adequate information to the patient of nature and extent of illness, untoward effects of the drugs and advice on lifestyle modification.

- Sub-optimal competency in communication skills.

- Poor monitoring and follow up with resultant inability to modify or intensify the therapeutic regime.

- Inability to ratify individual patient's selfmanagement.

Socio-economic:

- Unaffordable prescriptions.

- Inadequacy of the concerns of patient's beliefs and social set up.

\section{Therapy:}

- Complexity of medication regime and difficult schedule.

- Poly pharmacy.

\section{Health Care System:}

- Non-existent /Non-functional primary care referral system.

- Inability to organize well-structured training program in communication skills, for the physicians.

- No check and balance system.

\section{Discussion}

"Drugs do not work in patients who do not take them"

Charles Everette Koop (1916-2013)-Surgeon General of United States

The results of the study, although not unexpected in setup like ours, were disappointing. The adherence rate to medication alone was $42 \%$ while to medication plus lifestyle recommendations $27 \%$. This 
shows a lapse both on the parts of the patients and the prescribers.

"Health Literacy" has been defined as "the degree to which individuals have the capacity to obtain, process and understand basic health information and services needed to make appropriate health decisions" [15]. Sub-optimal health literacy is, undoubtedly, an important bearing on the problem. However, the lapse on the part of the prescribers for not being considerate or being deficient in communication skills necessitates prompt intervention. It is of interest to refer to an identical study in Jordon [16] where the therapeutic adherence rates of the diabetics were analyzed as following:

- $81.4 \%$ did not follow the diabetic meal plans

- $67.9 \%$ did not participate in physical exercise programme

- $61.9 \%$ did not monitor their blood glucose level at home

However, 91.9\% were highly adherent to the medication advice.

It is a melancholic reality that majority of our study population was unclear about the true nature of their disease process and pros and cons of therapeutic adherence/non-adherence. Strom et al [17] and Kvarnstrom et al [18], in Danish and Finnish studies respectively, gathered that the physicians frequently do not communicate to the patients about the basic information of the treatment plans. The patients may be left with concerns about adverse effects with lack of comprehension of their own disease. Koch et al, on the basis of a study in Netherlands, concluded that complete and accurate information plays an important role in the behaviour of patients, especially in control and management of disease [19]. In a study by van Delmen et al, the participating GPs agreed that the communication about adherence should be tailor made by not thoughtlessly applying guidelines but by paying attention to patients' needs [20]. Peschin et al, while speaking at the " 9 "th Power of Partnering (POP) Conference" advocated that improvement of health literacy and simplifying the terminology will help patients to better comprehend the complexity of their disease [21]. It is evident that, in our study, comprehensive information about the medications and lifestyle modifications was either not given to the patients or if given, not adequately picked by them.

The studies conducted in Canada [22], United States [23], Spain[24], Finland[18], Singapore[25] and Ghana[26] have the common inference that poor adherence to medication regimes, in diabetics, results in significantly worse clinical outcomes including inadequate glycemic control, increased use of healthcare resources, increased out-patient care, hospitalization and re-hospitalization, higher medical costs and markedly huge mortality rates.

The National Council on Patient Information and Education United States (NCPIE), in 2007, published a report "Enhancing Prescription Medication Adherence: A National Action Plan" to make recommendations for improving medication adherence, the emphasis was given on "Educate before you Medicate" [27]. Needless to say that, for the success of such a programme, the central position of the patient must be recognized. Ibn Sina (980-1037 $\mathrm{CE}$ ), the author of "Kitab al-Qanun fi-al-Tibb" justifiably graded "The First Text Book of Medicine on Earth" [28] has discussed this aspect in detail. While enumerating "Seven Doctrines of Preservation of Health", he highlighted key role of the individual in the form of "Mudawa Salookia" (Behaviour Modification) [29]. And this is what we must prioritize in a joint team approach to resolve the issue of improving therapeutic adherence.

The consequences of non-adherence are more pronounced in elderly, the fast-growing sector of global population. Estimates range from $40 \%$ to $75 \%$ [30]. The more serious issue lies in taking more of the drug, in the mistaken belief that by doing so the recovery would be speeded up. Conversely forgetfulness leads to under-utilization or overutilization of the regimen. As a result they are exposed to both under-adherence and overadherence.

Recourse to diverse care-providers (homeopaths, herbal medicine, natural healers, faith healers etc) because of low trust in the efficacy of prescription 
Citation: Siddiqui MH, Khan IA, Moyeen F, et al., "Identifying Barriers to Therapeutic Adherence in Type 2-Diabetes: A Complex and Multidimensional Clinical Issue”. Asp Biomed Clin Case Rep, vol.2, no.1: 22-28, 2019.

medication, for additional/alternate advice is our cultural issue. The affordability is also an important element. Atinga et al., [26] while enumerating factors influencing long term medication non-adherence among diabetics and hypertensives, in Ghana, identified that perception of inefficacy of the prescription medications turned to return to herbal medicines and spiritual healing because of their easy accessibility, perceived efficacy and affordability.

Complexity of the regimen (number and frequency) has an important bearing on the adherence [31]. In a systematic review of the association between dose regimen and medication compliance, Claxton et al concluded that the prescribed number of doses/per day is inversely related to compliance. Simpler less frequent dosing regime resulted in better compliance across a variety of therapeutic classes [32].

The "Federal Study of Adherence to Medications in the Elderly (FAME)", aimed to determine the effect of a pharmacy intervention programme on medication adherence and persistence identified the ways to improve adherence [33].

We need to highlight that a significant contributing factor in therapeutic non-adherence, in our study, was the cost of medication. It has been found that even in developed countries like Australia the out of pocket costs of medications' adversely affect the adherence in chronic diseases.[34].Needless to reiterate that economic problem is the main challenge in our set up where every expense on medical treatment is 'out of pocket'. Sir Frederick Grant Banting, in his Nobel Lecture on September 15, 1925, admitted "Insulin is not a cure for diabetes, it is treatment". The same is true of the modern anti-hyperglycaemic oral pills. Diagnosis of a chronic bothersome and incommodious disease like diabetes comes to the family as a strong blow. How can we expect optimal therapeutic adherence in view of the high cost of medication, for an unlimited period, in a middle class family with already over-stretched monthly budget?

\section{Conclusion}

Whereas, the problem of therapeutic non-adherence is the "end result of complex set of interwoven factors"
[35], it is still preventable. This needs only commitment.

"It always seems impossible until it is done" --Nelson Mandela (1918-2013 CE)

\section{Limitations of the study}

The study is qualitative with a small sample. There was no representation of the prescribers and those of the pharmacists. All the participants were without diabetes associated co-morbidities. It is well known that multiple diseases and resultant polypharmacy further challenge the good coordination of the health care.

\section{Recommendations}

Whereas the WHO recommends that the determinants be considered in 5 dimensions: socioeconomic factors, health care team and system related factors, condition related factors, therapy related factors and patient related factors [3], a larger multi-centre in-depth quantitative study (involving patients, prescribers and pharmacists ) needs to be done on priority basis. This would pave the way for planning a well-designed intervention programme.

\section{Ethical Considerations}

The procedures adopted in the present study were in accordance with the 1975 Declaration of Helsinki, as reviewed in October 2000.

\section{Source of Funding}

This research did not receive any specific grant from funding agencies in the public, commercial, or non-for-profit sectors.

\section{Conflict of Interest}

None

\section{Acknowledgement}

Dr. Murad Ahmad Khan (Vancouver BC Canada) and Dr. Hamza Iltaf Malik (Coventry United Kingdom) deserve special thanks for their kind, motivating and stimulating discussions throughout 
the conduct of this study.

\section{References}

[1] Kardas P, Lewek P, Matyjaszczyk M, “Determinants of patient adherence: a review of systematic reviews". Front Pharmacol, vol.4, no.91: 1-28, 2013.

[2] ADA, "Diagnosis and Classification of Diabetes mellitus-American Diabetes Association”. Diabetic Care, vol.33, no.suppl 1: s62-s69, 2010.

[3] WHO, "Adherence to long term therapies: Evidence for Action”. World Health Organization, Geneva: 2003.

[4] WHO, "Global Report on Diabetes". World Health Organization, Geneva: 2016.

[5] Meo SA, Zia I, Bukhari IA, et al., “Type 2 Diabetes mellitus in Pakistan:Current prevalence and future forecast”. J Pak Med Assoc, vol.66, no.12: 1637-42, 2016.

[6] Gellad W F, Grenard JL, Marcum ZA, “A systematic review of barriers to medication adherence in the elderly: Looking beyond cost and regimen complexity". Am J Geriatr Pharmacother, vol.9, no.1: 11-23, 2011.

[7] Wroe AL, "Intentional and unintentional nonadherence: a study of decision making". J Behav Med, vol.25, no.4: 355-72, 2002.

[8] Clifford S, Barber N, Horne R, "Understanding different beliefs held by adherers, unintentional nonadherers, and intentional nonadherers: application of the Necessity Concerns Framework". J Psychosom Res, vol.64, no.1: 41-46, 2008.

[9] Gupta S, Dhamija JP, Mohan I, et al., "Qualitative study of barriers to adherence to antihypertensive medication among rural women in India". Int $J$ Hyperten, vol.2019: 1-7, 2019.

[10] Lehane E, McCarthy G, "Intentional and unintentional medication non-adherence: a comprehensive framework for clinical research and practice? A discussion paper”. Int J Nurs Stud, vol.44, no.8: 1468-77, 2007.

[11] Vrijens B, De Geest S, Hughes DA, et al., "A new taxonomy for describing and defining adherence to medications". Br J Clin Pharmacol, vol.73, no5: 691705, 2012.

[12] Nilsson JLG, Andersson K, Bergkvist A et al., "Refill adherence to repeat prescriptions of cancer drugs to ambulatory patients". Eur J Cancer Care (Engl), vol.15, no.3: 235-37.
[13] van Geffen EC, Gardarsdottir H, van Hulten R, et al., "Initiation of antidepressant therapy: do patients follow the GP's prescription?”. Br J Gen Pract, vol.59, no.559: 81-87, 2009.

[14] Hugtenburg JG, Timmers L, Elders PJ, et al., "Definitions, variants, and causes of non-adherence with medication: a challenge for tailored interventions". Patient Preference Adherence, vol.7: 675-82, 2013.

[15] US Department of Health and Human Services. Healthy People, Washington DC: 2000.

[16] Khattab M, Khader YS, Al-Khawaldeh A et al., "Factors associated with poor glycemic control among patients with Type 2 Diabetes". J Diabetes Complications, vol.24, no.2: 84-89, 2010.

[17] Storm A, Benfeldt E, Andersen SE, et al., "Basic drug information given by physicians is deficient, and patients' knowledge low”. J Dermatolog Treat, vol.2o, no.4: 190-93, 2009.

[18] Kvarnström K, Airaksinen M, Liira H, "Barriers and facilitators to medication adherence: a qualitative study with general practitioners". BMJ Open, vol.8, no.1: e015332, 2018.

[19] Koch T, Kralik D, Sonnack D, "Women living with type 2 diabetes: The intrusion of illness". J ClinNurs, vol.8, no.6: 712-22, 1999.

[20] van Dulmen S, van Bijnen E, "What makes them (not) talk about proper medication use with their patients? An analysis of the determinants of GP communication using reflective practice". Int J Pers Cen Med, vol.1, no.1: 27-34, 2011.

[21] Peschin S, Doane CM, Roberts ME, et al., "Patient Adherence:Identifying Barriers and Defining Solutions”. Am J Pharm befits: 2010.

[22] Brundisini F, Vanstone M, Hulan D, et al., "Type 2 diabetes patients' and providers' differing perspectives on medication nonadherence: a qualitative meta-synthesis". BMC Health Serv Res, vol.15, no.516: 1-82, 2015.

[23] Polonsky WH, Henry RR, "Poor medication adherence in type 2 diabetes: recognizing the scope of the problem and its key contributors". Patient Prefer Adherence, vol.10: 1299-307, 2016.

[24] Barba EL, de Miguel MR, Hernandez-Mijares A, et al, "Medication adherence and persistence in type 2 diabetes mellitus: perspectives of patients, physicians and pharmacists on the Spanish health Care system". 
Citation: Siddiqui MH, Khan IA, Moyeen F, et al., "Identifying Barriers to Therapeutic Adherence in Type 2-Diabetes: A Complex and Multidimensional Clinical Issue”. Asp Biomed Clin Case Rep, vol.2, no.1: 22-28, 2019.

Patient Preference Adherence, vol.11: 707-18, 2017.

[25] Lin LK, Sun Y, Heng BH, et al., "Medication adherence and glycemic control among newly diagnosed diabetes patients". BMJ Open DiabRes Care, vol.5, no.1: eooo429, 2017.

[26] Atinga RA, Yarney L, Gavu NM, "Factors influencing long-term medication non-adherence among diabetes and hypertensive patients in Ghana: A qualitative investigation”. PLoS One, vol.13, no.3: e0193995, 2018.

[27] NCIPE, "Enhancing Prescription Medicine Adherence: A National Action Plan”. Rockville M.D.: 138, 2007.

[28] Ronan CA, "The Cambridge Illustrated History of World's Science”. Cambridge University Press: 1984.

[29] Khan MA,Raza F, Khan IA, "IBN Sina and the roots of the seven doctrines of preservation of health". Acta Med Hist Adriat, vol.13, suppl.2: 87-102, 2015.

[30] Salzman C, "Medication compliance in the elderly”. J Clin Psychiatry, vol.56, suppl-1: 18-22, 1995.
[31] Zekovic M, Krajnovic D, Marinkovic V, et al., "The Complexity of Adherence Issue: A Review of its scope and determinants". Acta Medica Medianae, vol.55, no.1: 51-57, 2016.

[32] Claxton AJ, Cramer J, Pierce C, "A systematic review of the association between dose regimens and medication compliance". Clin Ther, vol.23, no.8: 1296-310, 2001.

[33] Walter Reed Army Medical Center, "Federal Study of Adherence to Medications in the Elderly (FAME)”. Clinical Trials.gov: 2006.

[34] Heidari P, Cross W, Crawford K, "Do out of pocket costs affect medication adherence in adults with rheumatoid arthritis? A systematic review". Semin Arthritis Rheum, vol.48, no.1: 12-21, 2018.

[35] Forsyth P, Richardson J, Lowrie R, "Patientreported barriers to medication adherence in heart failure in Scotland". Int J Pharm Pract: 2019. 